\title{
Striking the Right Tone
}

\section{A Proposed Modification to the Development of User Support System Design}

Anna Pollard and Delfryn Thomas

School of Computing, Information Systems \& Mathematics, South Bank University, Borough Road, London SE1 OAA, Tel: +44 (0) 207815 \{7407|7481\}, Fax: +44 (0) 207815 7499, E-mail: \{pollara|del\}@sbu.ac.uk

\section{DEFINITION OF THE PROBLEM}

The interaction between a computer support system and its user is a special case of interpersonal interaction. Here the computer support system acts as a proxy for its author(s). The field of Human Computer Interaction (HCI) implicitly recognises this relationship and considers principles that will facilitate it (Shneiderman 1998). However, despite the application of engineering principles to the design of user support systems, it is still difficult to specify the interpersonal 'tone' of a system with precision. A corresponding problem exists in defining the needs of a computer support system's target clientele.

It is widely recognised (Wiemann et al. 1996, Knapp et al. 2000, Parks 1994), in studying interpersonal interaction, that such interactions can be analysed in terms of the regulation (or control) and solidarity (or collaboration) associated with them. Parks believes that the control perspectives lie at the heart of almost all definitions of communication competence and Knapp and Vangelisti, who concur, discuss the concept of negative control values (such as helplessness and submissiveness). These latter also introduce the concept of negative values in relation to the prospective of solidarity. In general, these analyses appear to have focused on one or other of the two variables - regulation and solidarity - or on a combination of both, rather than on both as separate independent variables.

The original version of this chapter was revised: The copyright line was incorrect. This has been corrected. The Erratum to this chapter is available at DOI: 10.1007/978-0-387-35611-2_22 
Taxonomies used in this work have tended to be domain based and limited. The issue of analyst bias also causes concern.

\section{ANALYSIS OF STATEMENTS FOR THEIR REGULATORY AND SOLIDARITY INDUCING CONTENT}

Ongoing work at South Bank University (Pollard \& Thomas 2000) has developed an analytic technique that considers both variables and avoids the problem of analyst bias. This technique uses a rule base to look for components of a communication that tend to induce regulation (we term these Regulation Inducing Components - RIC) and components that tend to induce solidarity (which we term Solidarity Inducing Components - SIC). The form of the associated taxonomy is domain independent and, in its final form, will be comprehensive.

This taxonomy is described fully in Pollard and Thomas (2001). It adopts Knapp's concept of negative values for the classification of both Regulation Inducing Components (RIC values) and Solidarity Inducing Components (SIC values). The result of such an analysis for a set of statements is displayed on a two-dimensional classification grid. The RIC and SIC axes are orthogonal and experience shows that, in a general RIC-SIC analysis, differing areas of the resulting graph can be related to differing implied impacts of the statements involved. Thus, for example, statements that map to the positive RIC, positive SIC quadrant of the diagram are seen as likely to have the effect of 'managing' the recipient to differing degrees. In the same way, statements that map to the negative RIC, positive SIC quadrant are seen as having a tendency to develop 'fellowship'.

The analysis of statements by this technique is complicated by the fact that the analysis must take into account the context in which the statement is made. However, in the case of a user support system addressing a particular target clientele, the context is stable and as such does not complicate the analysis.

\section{APPLICATION OF RIC-SIC ANALYSIS IN IDENTIFYING THE 'TONE' OF USER SUPPORT SYSTEMS}

Figure 1 illustrates the application of the RIC-SIC analysis technique to a small number of samples drawn from two Microsoft user support systems 
(Pollard \& Thomas, 2001). These systems, the Visual Basic user support system and Microsoft's Office Assistant, exhibit very different 'tones' and this is reflected in the way that the statements taken from them map onto the classification grid. The classification grid, Figure 1, shows the Visual Basic support system as having a consistent tone that is both guiding (RIC value $=$ 1) and supportive (SIC value $=3$ ). In contrast to this, the majority of the Office Assistant samples show this user support system as subservient in attitude (RIC value $=-3$ ) and supportive (SIC value $=3$.)

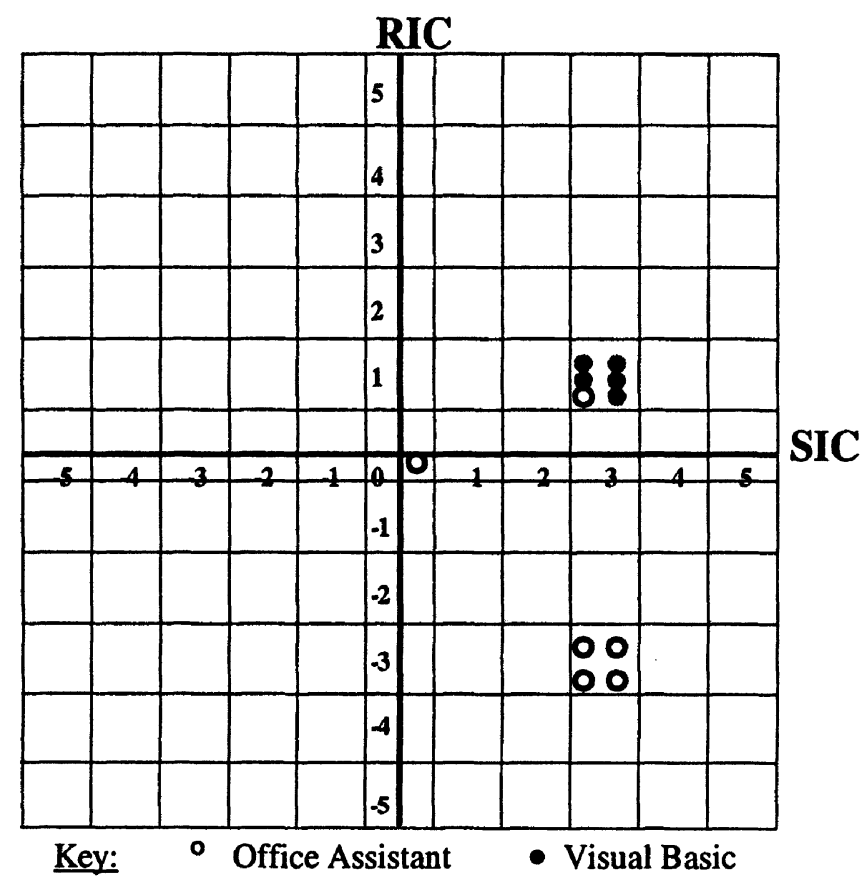

Figure 1. RIC-SIC Analysis of Samples from two Microsoft User Support Systems

\section{CONCLUSION}

As shown by Figure 1, RIC-SIC analysis is capable of distinguishing between the tones of different user support systems in a quantifiable way. While the current level of resolution of the analysis technique may need to be increased, the availability of a technique that yields a quantifiable metric opens up the possibility of a more engineered approach to both the specification and testing of the 'tone' aspects of user support systems.

In the presence of tables relating the support system's target clientele to suitable ranges of RIC-SIC values, a designer would be able to specify the tonal elements of the user support system interface in terms of these ranges. 
Similarly testing of the interface(s) for a suitable tone could then be carried out directly through a RIC-SIC analysis of the final system and comparison of the analytic results with those specified by the designer. Such an approach would reliably save the cost of user acceptability testing (for 'tone') since it would be reusing the testing work done in the setting up the tables used by the designer.

Research work will be needed both to establish the required granularity of the results produced by the analytic method, and to generate tables capable of distinguishing between the different user target groups in terms of the RIC-SIC ranges that are suitable for them.

\section{REFERENCES}

Knapp, M.L. \& Vangelisti, A.L. (2000) "Interpersonal Communication and Human Relationships" (4th edition), Allyn \& Bacon, Needham Heights, MA.

Parks, Malcolm R. (1994), "Communicative Competence and Interpersonal Control", in Knapp, M.L. \& Miller, G.R. (eds.), "Handbook of Interpersonal Communication" (2nd edition), Sage Publications, Thousand Oaks, CA.

Pollard, A.J. \& Thomas, D. (2000), "CyberPower and CyberSolidarity", in Simpkins, Scott, Spinks, C.W., \& Deely, John (eds.), Semiotics 1999, Peter Lang, New York, pp 243-261.

Pollard, A.J. \& Thomas, D. (2001), Technical Report SBU-CISM-01-10, South Bank University, London. (http://www.sbu.ac.uk/ pollara/semiotics/techrep-CISM-01-10.doc)

Shneiderman, Ben (1998), "Designing the User Interface" (3rd edition), Addison-Wesley, Reading, MA

Wiemann, John M. \& Giles, Howard (1996), "Communication in Interpersonal and Social Relationships" , in Hewstone, Miles, Stroebe, Wolfgang, \& Stephenson, G.M. (eds.),, "Social Psychology" (2nd ed.), Blackwell, Oxford. 